\title{
WORK LIFE BALANCE AND SERVICE DELIVERY AMONG WOMEN ENTREPRENEURS IN SOUTH- WESTERN NIGERIA
}

\section{Mutiat Oyinlola Kuranga ${ }^{1}$}

Abstract

\begin{abstract}
Businesses in the twenty first century are characterized by persistent changes, uncertainties and undue pressure to meet demands and increase productivity. For women entrepreneurs, they are expected to combine this with the statutory responsibility of taking care of their children, families and home front. Managing these different roles and responsibilities usually influences the business performance and family life and may impact their service delivery. Hence, the study examined the impact of work-life balance on service delivery among women entrepreneurs in south-western Nigeria. A total of 379 respondents were selected from a population of 25,122 members of the Nigeria union of tailors in Lagos, Oyo and Osun state using multistage sampling techniques. Primary data was collected through the use of a structured self-administered questionnaire and a structural equation model (SEM- PLS) was adopted for the analysis. The result shows work demands, wellbeing, family workload and spousal support with coefficients $0.219,0.101,0.061$ and 0.563 . The study also found that every unit change of work-life balance would lead to a 0.792 unit change in service delivery. Therefore, the study concludes that work-life balance contributes significantly to the service delivery of women entrepreneurs. The study recommends that women entrepreneurs should effectively manage their work and family roles, ensure creativity and flexibility in their work domains and seek support to enable them to deliver efficient service and achieve overall performance in their business.
\end{abstract}

JEL classification: $01, \mathrm{~J} 1$

Keywords: : work-life balance, service delivery, women entrepreneurs, performance

\footnotetext{
${ }^{1}$ Department of Business and Entrepreneurship; College of Humanities, Management and Social Sciences, Kwara State University, Malete, Nigeria, e-mail: houyinlola@gmail.com, ORCID: 0000-0003-3236-0791.
} 


\section{INTRODUCTION}

Over the years, women entrepreneurs have been recognized as significant contributors to the growth and development of the economy by transforming ideas into action, identifying opportunities in the environment, gathering resources and utilizing the opportunities. Women's entrepreneurship has received a lot of attention from researchers, academicians, government, decision makers and society at large. They are now considered important forces in the economic development of their nations as many women go into alternative avenues of generating income, with a greater number of women setting up businesses, taking risks and ensuring performance. Businesses are now competing globally and there is continuous evolvement to meet the demands and expectations of customers. The resultant effect of this scenario is overwork for the business owner without considering family obligations and responsibilities such as leisure, child and elderly care among others.

Women are statutorily responsible for taking care of the home. Women in business tend to view their business as a mutually connected system and not merely as a separate economic system. This relationship creates a situation in which the business is assimilated into the life of the woman entrepreneur. She is at the center of a number of relationships: family, community and business. When a woman starts her own business, she is not creating a separate economic entity, but is assimilating a new system of a relationship dependent business. As a result, female entrepreneurs, as working women and mothers, undertake multiple roles in the family and in the business. These roles trigger conflict when they simultaneously deal with increasing commitments at work and unreduced family obligations. Despite the active roles of these women in business, paid employment and entrepreneurship, their roles as wives, mothers, sisters, daughters and home -keepers need to be maintained.

Women now perform dual roles, in their career and household, and due to the multiple roles they undertake, they are more likely to experience inter-role conflicts. Women face conflicts between work and family demands, and pressures arising from work coupled with the unfavorable economic situation in Nigeria hamper many women from performing their statutory traditional roles in the family. Also, traditional roles performed by women at home can impact work outputs and outcomes which invariably may have effect on entrepreneurial innovation and creativity. Previous research (Ahmad, 2010; Abdulraheem, 2014) identified issues such as the family size, the age and number of children, the number of hours worked outside the home as contributors to women's psychologi- cal distress owrell-being. These specific strains and stresses among women in their marital, occupational and household roles can become an overload and influence their behavioral outcomes and thus impact service delivery in their businesses.

Despite these challenges that women face they are still solely responsible for the success of their businesses as entrepreneurs. Women entrepreneurs' financial sustenance, personal satisfaction, and the ability to balance work and non-work responsibilities are crucial success factors. They are not exempted from the routine demands that society places on them as women and at the same time they are responsible for driving the success and performance of their businesses. Increasing women's participation in entrepreneurship, an active labor force, job demands and the diversity of family constellations have impact on their output, hence, the need to assess how women entrepreneurs balance their work and non-work domains and its effect on their entrepreneurial performance.

\section{LITERATURE REVIEW \\ CONCEPT OF WORK-LIFE BALANCE}

Work-life balance does not mean an equal balance between professional and personal life. It is careful synchronization of an individual's varied pursuits that may include family, leisure, social obligations, health, career and spirituality with work. While some of the pursuits need greater attention, others may require lesser focus. Work-life balance is one of the most challenging issues faced by women in the 21st century (Abdulraheem, 2014). There is an increasing concern for managing the demands from work and family for women both in paid employment and entrepreneurship. For those in paid employment, government policies and organizational initiatives have been deployed to foster the work-life balance of their employees. These initiatives include education programs, leave policies, childcare, telework, work schedules and other practices that contribute to employees' worklife balance. Government policies also ensure that employment guidelines and regulations are followed by organizations to promote work-life balance.

Twenty-first century businesses are characterized by persistent changes, uncertainties and undue pressure to meet demands and increase productivity. These changes disturb the balance in the lives of women entrepreneurs causing confusion and stress. This is also fuelled by extreme levels of competitiveness in the business sphere posing new challenges and problems to owners. Technological advancements and new inventions in the fashion world have impacted the socio-cultural context by 
introducing multi-cultural lifestyles. In the midst of all this, the compelling need for growth in all spheres, for individuals as well as their businesses have resulted in imbalance in the lives of the women. The incessant demands on their time and effort to enhance performance have created enormous stress and pressure. This has led to disequilibrium between work-life and family life. Consequently, the quality of life of most women entrepreneurs has been compromised because of long hours they spend at work and the need to carry work home.

Work-life balance is one of the most relevant human resource practices in relation to productivity and performance of the organization (Ojo, Salau \& Falola, 2014). Work-life balance is a very important phenomenon that is of great concern to various employees in both the private and public sectors (Abdulraheem, 2014). It goes beyond prioritizing the work role and one's personal life, it also affects the social, psychological, economical and mental well-being of the individual. Every individual is an integral part of the family in particular and the society in general. Work-life balance has implication on employee attitudes, behaviors as well as organizational effectiveness (Eby, Casper, Lockwood, Bordeanx \& Brindley, 2005).

Taking all of the above into consideration, work-life balance is herein conceptualized as the broad assessment that individual and environmental resources are sufficient to meet demands, evidenced by reduced conflict and greater facilitation, such that integration is perceived between work and personal life domains resulting in positive general health, satisfaction, behavioral and work performance outcomes. This conceptualization parallels and expands on previous handling of the work-life balance concept because it takes into account the antecedents of work-life balance(individual and environmental work and non-work demand and resource characteristics), aspects of the work-family interface (reflected in the degree of conflict and facilitation present), the individual's perception of work-life balance (through a validated work-life balance measure) and the personal and organizational consequences of balance (such as general health, satisfaction, behaviors and performance).

\section{SERVICE DELIVERY}

Service delivery refers to the actual delivery of a service and product to the customers and clients (Lovelock \& Wright, 2002). It focuses on the where, when, and how a service product is delivered to the customer and whether this is fair or unfair in nature. Service-based businesses often take advantage of any opportunity to distinguish themselves from their competitors and the best way to do this is to foster strong customer relationships based on the quality of service. Customer expectations are beliefs about service delivery that are used as a base or bench mark against which the performance of the service is judged (Lodorfos, Kostopoulos \& Kaminakis, 2015). While service implementation, system details, and service management are all important, Customers have different types of expectations about service which can be grouped into desired service and adequate service. The desired service means the level of service the customer hopes to receive or wishes to receive from the provider. Adequate service is the level of expectation when the customer recognizes that his hope to achieve desired service is not possible.

According to Mullen and Lambie (2017), it is vital to define the scope of service for effective service management, making sure that the service provider and customer are on the same page regarding what to expect (or not expect) from the service offerings. This includes what your services do and don't contain, eligibility, entitlements, potential limitations, costs and more. Establishing a service culture and concept is instrumental to the success of every service organization. This service culture should include principles, methodology, philosophy, relationship and interaction with the customers and organization as a whole. The service culture is strictly internal and requires concerted efforts of the service delivery team ranging from the business owner, management and the employees.

To deliver efficient services, business owners are saddled with the responsibility of ensuring that the available resources are utilized in the most profitable manner to achieve competitive advantage. Employees should be aligned with the specific set of overarching principles of the service concept as this translates directly to the customers (Vargo \& Robert, 2008; Lodorfos, Kostopoulos \& Kaminakis, 2015). For business owners, a lot of effort goes on behind the scenes to ensure efficient service is delivered to customers, it gives a reflection of individual capabilities, team management, time management, skill adaptability and relationship management. Like any organization, the individual business owner has a limited amount of resources and needs to understand the current resource requirements, anticipate future resource needs, track employee schedules and capacities to ensure effective service delivery. With this visibility into the resource utilization, one can schedule in accordance with current projects, forecast sales, and ensure that no resource is over- or underutilized. This definition of service delivery goes beyond the customer, the best service organizations also clearly delineate any internal efforts needed to provide and support their service. 


\section{THEORETICAL REVIEW}

This study is anchored on the theoretical underpinning of the spillover theory as well as the job- demand resource model of entrepreneurs. These theories highlight that work and family are not isolated domains but are mutually beneficial spheres which are connected.

\section{SPILLOVER THEORY}

Spillover is described as a relationship between work and family, where positive work experiences would be associated with positive family experiences and negative work experiences would be associated with negative family experiences. Spillover is a process by which a person's experience in one domain affects their experience in another domain. Spillover occurs where the events of one environment affect the other. Theoretically, spillover is perceived to be one of two types: positive or negative (Lavassani \& Movahedi, 2018). Spillover occurs where the events of one environment affect the other. According to this theory workers carry the emotions, attitudes, skills and behaviors from their work role into their family life and vice versa. Spillover as the most popular view of relationship between work and family, considers multidimensional aspects of work and family relationship. These multidimensional aspects are: positive or negative work to family and family to work effects (Kirchmeyer, 2000)

In spillover theory work and family operate as one entity. There is no boundary between the workplace and the home, therefore, what happens at work will also happen at home. According to Lavassani and Movahedi, (2018), two types of spillover exist, horizontal spillover and vertical spillover. Horizontal spillover shows how one life domain influences a neighboring domain. For example, job satisfaction may influence feelings of satisfaction in the family life domain and vice versa. On the other hand, in order to understand the concept of vertical spillover, it is necessary to first understand the concept of domain hierarchy. Individuals rank the life domains in hierarchical order in their minds. At the top of the hierarchy is the most super ordinate domain, namely overall life. Feelings in this domain reflect life satisfaction, personal happiness or subjective well-being. The other important life domains such as family, job, leisure, community, etc. are subordinate to the most super ordinate life domain. Satisfaction/dissatisfaction within any of the main life domains 'spills over' to the most super ordinate domain, therefore influencing overall life satisfaction. Moreover, the vertical spillover can be either bottom-up or top-down. Critics of the spillover theory have generally termed it as lacking continuation, extension, familiarity and similarity (Edwards \& Rothbard, 2000; Lavassani \& Movahedi, 2018).

\section{JOB DEMANDS-RESOURCES MODEL FOR ENTRE- PRENEURS}

The theoretical basis of this study is the job demandsresources model (JD-R Model) by Bakker \& Demerouti 2007. This model is commonly used in the literature on work engagement and work-related strain. The central assumption in the job demands-resource model is that work-related strain develops when (certain) job demands are high and when (certain) job resources are limited, leading to exhaustion and undermining work engagement (Bakker, Demerouti \& Verbeke, 2004). In contrast, when job resources are high, the motivational process is activated, leading to work engagement and higher work performance (Schaufeli \& Bakker 2004; Bakker et al. 2004). Among entrepreneurs, different relationships of the JD-R Model are investigated in various studies, however, the classification of Dijkhuizen et al. (2014) of entrepreneurial job demands which were time demands; uncertainty and risk; and responsibility are commonly used.

The practical implication of this model provides the researcher with the understanding that entrepreneurs have a sense of energetic and effective connection with their work activities and they see themselves as able to deal well with the demands of their job (Schaufeli \& Bakker, 2004). Work-related strain on the other hand refers to long-term exhaustion from work, and diminished interest which could be as a result of work or other factors (Leiter, Bakker \& Maslach, 2014).A central element of the JD-R Model is the idea that every occupation has its own specific working conditions and risk factors associated with work engagement and work-related strain. For women entrepreneurs, coping with a high level of uncertainty, responsibility, risks, and a heavy workload alongside their stereotyped roles is demanding (Dijkhuizen et al. 2014; Drnovsek, Örtqvist \& Wincent, 2010). These indicators can be considered job demands, which directly relate to workrelated strain. It is therefore not surprising that entrepreneurs overall experience high stress levels (Harris, Saltstone \& Fraboni, 1999; Wincent \& Örtqvist, 2009) and this could practically have a consequence on their performance.

\section{EMPIRICAL REVIEW}

McGowana, Redeker, Cooper and Greenan (2012) carried out a research on female entrepreneurship and the management of business and domestic roles: Motivations, expectations and realities in Northern Ireland. The objective of the study was to explore the motivations, expectations and actual experiences of women entrepreneurs on entrepreneurship, and the extent to which entrepreneurship really offers an improved work/family 
'balance'. The research adopted an exploratory qualitative study among 14 women entrepreneurs, and it focused on the entrepreneurial journeys of the women as they established and managed their ventures, whilst balancing domestic/familial demands. In-depth interviews were conducted, and this gave insights into their motivations, expectations and the realities of their experience. The study concluded that women entrepreneurs should recognize the advantages and disadvantages of having control of one's venture but also approach entrepreneurship with a realistic and unclouded view and awareness of the commitment required to be a success.

Dijkhuizen, Gorgeivsk, Veldhoven and Schalk (2014) conducted a cross-sectional study on feeling successful as an entrepreneur: a job demands-resources approach among 277 Dutch entrepreneurs. The study investigated how entrepreneurs' job demands relate to their workrelated strain and work engagement, as well as their feelings of subjective success. A structural equation model was used for the analysis and results of the study show that work-related strain is related to both less personal and less financial subjective business success. Work engagement is related to higher personal, but not financial subjective business success. The practical implication of these findings is that entrepreneurs can achieve an important competitive advantage over other entrepreneurs if they can learn to deal effectively with job demands and work-related strain. The challenge for policy makers is to get more information about how to assist business owners in eliminating and preventing work-related strain in order to achieve higher subjective financial and personal success.

Ugwu, Orjiakor, Enwereuzor, Onyedibeand Ugwu, (2016) carried out research on business-life balance and wellbeing: exploring the lived experiences of women in a low to-middle income country in Nigeria. The objective of the study was to explore the conceptions of balance and wellbeing of business women who trade on petty goods and earn very little in a low-to-middle income country (LMIC). The research adopted a qualitative approach, and twenty women were interviewed using a semi-structured guideline and analysis was conducted using interpretative phenomenology. The results showed that conceptions of balance for these women incorporated the notions of satisfactory progress across roles, proper time apportionment to roles, conditional balance as well as harmony and synchrony across roles. Their conception of business life roles was deemed much more integral. Negative physical and psychological experiences impacting health and wellbeing were identified as culminating result of both roles and were considered a normal part of living. In conclusion, there is a strong overlap between what balance means for petty trading women and employees. However, the unique social platform offers a more communal perspective of issues in pursuing balance.

Talreja (2017) conducted a research on women's entrepreneurship and work-life balance in India. The objective of the study was to examine how women entrepreneurs maintain a balance between the household and entrepreneurial work. A sample of 80 women entrepreneurs was selected randomly from the Kota district of Rajasthan and the primary data collected through the questionnaire. The study found that most of the women are overwhelmed by the conflicts that arise from domestic and entrepreneurial duties. It recommended that family members of the women entrepreneurs should encourage them by sharing the house hold responsibilities, moral support and making suitable adjustment for smooth running of their firms.

\section{METHODOLOGY}

The study adopted a cross sectional survey to evaluate and measure impact of work-life balance on service delivery among women entrepreneurs in South-western Nigeria. This survey method assisted with flexibility in terms of data collection and enabled it to gain an in-depth and better understanding of the variables under study. A quantitative method was adopted, and this method focused on determining the cause, effect and relationships of work-life balance and service delivery of the women entrepreneurs. This approach also gave an opportunity for results that had a broader perspective of the research problem.

This study focused on women tailors in Southwestern Nigeria as it is one of the fastest growing industries that have opened entrepreneurial opportunities to small businesses particularly among females in Nigeria. The Nigerian Union of Tailors is the association of tailors operating in the informal sector for members who are not registered under the corporate affairs commission (CAC). The population of the study comprises the members of the Nigeria union of tailors in south-western Nigeria, however, Lagos, Oyo and Osun states were purposively selected as they account for over $60 \%$ of the total population in south-western Nigeria.

The total number of women tailors/fashion designers registered with the association in the study area was 25,122 members and a sample of 379 respondents were selected for the study using Krejie and Morgan (1970). A primary method of data collection was adopted through the use of a structured questionnaire and the data was analysed usinga structural equation model (SEM), and partial least square (PLS) method. Structural equation 
model (SEM), partial least square PLS was adopted as it is known for providing a robust outcome even in the presence of multicollinearity within blocks of manifest and between latent variables. The study examined work-life balance using work and family related variables which were work demands, family workload, well-being and spousal support as the independent variables while service delivery was the dependent variable. The Cronbach alpha coefficient of the variables of work-life balance value of 0.779 showed adequate levels of internal consistency as a Cronbach alpha coefficient of 0.7 and above is acceptable as reliable.

Table 1: Frequency Distribution of the Respondents' Demographic Characteristics

\begin{tabular}{|c|c|c|c|c|}
\hline Variables & Value Label & Frequency & Percentage & Cumulative $\%$ \\
\hline \multirow{6}{*}{ Age Distribution } & $16-25$ & 70 & 18.4 & 18.4 \\
\hline & $26-35$ & 85 & 22.4 & 40.8 \\
\hline & $36-45$ & 103 & 27.2 & 68.0 \\
\hline & $46-55$ & 73 & 19.3 & 87.3 \\
\hline & 56 and above & 48 & 12.7 & 100.0 \\
\hline & Total & 379 & 100.0 & 100.0 \\
\hline \multirow{5}{*}{$\begin{array}{l}\text { Level of Educa- } \\
\text { tion }\end{array}$} & Informal education & 18 & 4.7 & 4.7 \\
\hline & Elementary/primary school & 78 & 20.6 & 25.3 \\
\hline & Secondary school & 118 & 31.1 & 56.4 \\
\hline & Post-secondary school & 89 & 23.5 & 79.9 \\
\hline & Graduate & 76 & 20.1 & 100 \\
\hline \multirow{5}{*}{$\begin{array}{l}\text { Number of years in } \\
\text { business }\end{array}$} & Below 5 years & 59 & 15.6 & 15.6 \\
\hline & 6 to $10 y e a r s$ & 115 & 30.3 & 45.9 \\
\hline & 11 to 15 years & 86 & 22.7 & 68.6 \\
\hline & 16 to 20 years & 119 & 31.4 & 100 \\
\hline & Total & 379 & 100.0 & 100 \\
\hline \multirow{5}{*}{$\begin{array}{l}\text { Duration of } \\
\text { membership in } \\
\text { association }\end{array}$} & Below 5 years & 63 & 16.6 & 16.6 \\
\hline & $6-10$ years & 119 & 31.4 & 48.0 \\
\hline & $11-15 y e a r s$ & 78 & 20.6 & 68.6 \\
\hline & 16 - 20 years & 119 & 31.4 & 100 \\
\hline & Total & 379 & 100 & 100 \\
\hline
\end{tabular}

Source: Author's Computation (2020) 


\section{FINDINGS AND DISCUSSIONS DEMOGRAPHIC CHARACTERISTICS}

Table 1 gives demographic characteristics of the respondents of the study. The age distribution indicates that the respondents are adults who are in the active age of childbearing and nurturing which is an important contributor to decisions that relate to work-life balance. Also, all of the respondents are registered members of the association and as such have ample experience in tailoring which makes them appropriate to give insights into how they manage their business and family. The level of education and years of experience of the respondents gives an insight into their understanding and measurement of quality service delivery in their business.

Table 2: Pearson Correlation Analysis of the Variables

\begin{tabular}{|c|c|c|c|c|c|}
\hline & & work demand & family workload & spousal support & well-being \\
\hline \multirow{3}{*}{ work demand } & Pearson Correlation & 1 & $.197^{* *}$ & $.454^{* *}$ & $.582^{* *}$ \\
\hline & Sig. (2-tailed) & & .000 & .000 & .000 \\
\hline & $\mathrm{N}$ & 379 & 379 & 379 & 379 \\
\hline \multirow{3}{*}{ family workload } & Pearson Correlation & $.197^{* *}$ & 1 & $.443^{* *}$ & $.583^{* *}$ \\
\hline & Sig. (2-tailed) & .000 & & .000 & .000 \\
\hline & $\mathrm{N}$ & 379 & 379 & 379 & 379 \\
\hline \multirow{3}{*}{ spousal support } & Pearson Correlation & $.454^{* *}$ & $.443^{* *}$ & 1 & $.754^{* *}$ \\
\hline & Sig. (2-tailed) & .000 & .000 & & .000 \\
\hline & $\mathrm{N}$ & 379 & 379 & 379 & 379 \\
\hline \multirow{3}{*}{ well-being } & Pearson Correlation & $.582^{* *}$ & $.583^{* *}$ & $.754^{* *}$ & 1 \\
\hline & Sig. (2-tailed) & .000 & .000 & .000 & \\
\hline & $\mathrm{N}$ & 379 & 379 & 379 & 379 \\
\hline
\end{tabular}

Source: Author' Computation (2020)

\section{ANALYSIS OF VARIABLES}

As shown in Table 2, the correlation coefficient $r$ indicates a positive correlation between the variables. This is revealed by the results having figures greater than 0 and less than 1 for the four latent variables indicating a strong association. This positive correlation implies that the variables increase or decrease together. Hence, a unit change in work demand, family workload, wellbeing and spousal support gives a variance in service delivery. It also shows that work demand, family workload, wellbeing and spousal support have a significant effect on service delivery. All these explanatory variables have a positive significance on the explained variable.

Similarly, the high percentage of the correlations between the exogenous latent constructs were below the suggested threshold values of 0.90 or more, which suggests that the exogenous latent constructs were independent and not highly correlated. This is in line with the position of Hair, Hult, Ringle and Sarstedt (2014), that a correlation coefficient of 0.90 and above indicates multicollinearity between exogenous latent constructs. 
Table 3: Multicollinearity Test

\begin{tabular}{|c|c|c|c|}
\hline Variables & N & VIF & Tolerance \\
\hline Work demands & 379 & 1.589 & .629 \\
\hline Family Workload & 379 & 1.590 & .629 \\
\hline Well being & 379 & 2.320 & .431 \\
\hline Spousal support & 379 & 3.561 & .281 \\
\hline
\end{tabular}

Source: Author's field survey (2020)

Following the examination of the correlation matrix for the exogenous latent constructs, Table 3 shows variance inflated factor (VIF), tolerance value and condition index to detect multicollinearity problem. The results indicate the VIF values and tolerance values for the exogenous latent constructs where all VIF are less than 5 and tolerance value greater than 0.20 . This implies that the multicollinearity requirement were met.

\section{TEST OF HYPOTHESIS}

$\mathrm{H}_{01}$ : Work-life balance has no significant effect on service delivery of women entrepreneurs in South-western Nigeria;

\section{SUB HYPOTHESES}

H01a: Work demands have no significant effect on service delivery of women entrepreneurs in South-western Nigeria;

$\mathrm{H}_{01 \text { b: }}$ Family workload has no significant effect on service delivery of women entrepreneurs in South-western Nigeria;

$\mathrm{H}_{01 c:}$ Well-being has no significant effect on service delivery of women entrepreneurs in South-western Nigeria;

$\mathrm{H}_{01 \mathrm{~d}}$ : Spousal support has no significant effect on service delivery of women entrepreneurs in South-western Nigeria;

Figure 1: Measurement Model (Algorithm testing) Service delivery

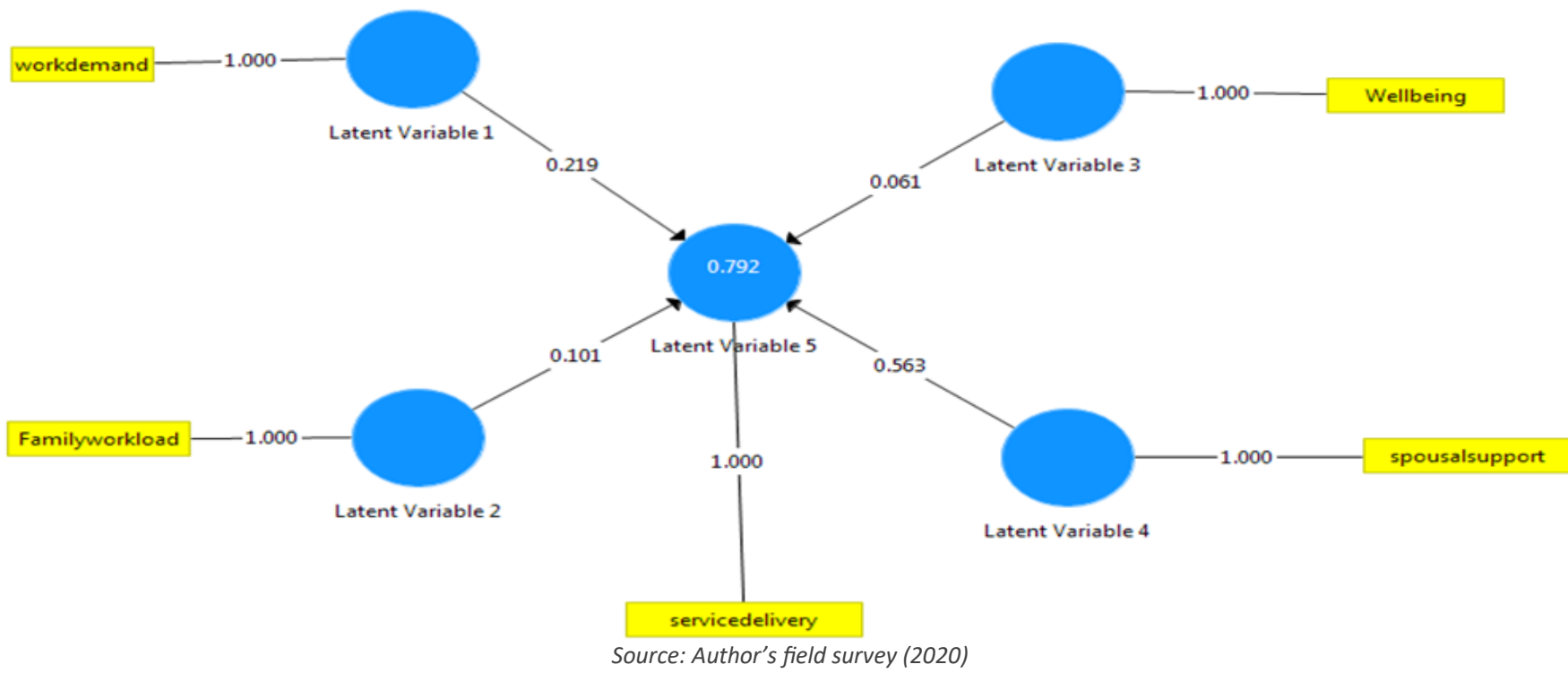


Figure 1 above show target endogenous variable variance. The coefficient of determination, $\mathrm{R}^{2}$, is $0.79 \%$ for the in-service delivery endogenous latent variable. This means that work demand, family workload, wellbeing and spousal support moderately explain $0.79 \%$ of the variance in service delivery.

The inner model suggests that work demand, family workload, wellbeing and spousal support have a significant effect on service delivery.

Table 4: Path Coefficient: Service Delivery (SD)

\begin{tabular}{|c|c|c|c|c|c|}
\hline & Original Sample & Sample Mean & $\begin{array}{c}\text { Standard Devia- } \\
\text { tion }\end{array}$ & T Statistics & P Values \\
\hline Work demands-> SD & 0.517 & 0.525 & 0.068 & 0.219 & 0.000 \\
\hline Family workload -> SD & -0.007 & -0.012 & 0.125 & 0.101 & 0.075 \\
\hline Well-being->SD & 0.186 & 0.184 & 0.039 & 0.061 & 0.000 \\
\hline Spousal support-> SD & 0.300 & 0.298 & 0.135 & 0.563 & 0.027 \\
\hline
\end{tabular}

Source: Author's field survey (2020)

In the Hypothesis testing, the SEM result indicated that spousal support being a variable of the independent construct is positively related to service delivery. The result indicated that spousal support has a significant effect on service delivery at $(\beta=0.300, t=0.563, p$ $<0.027$ ), Hence, $\mathrm{Ho}_{4}$ : Spousal support has no significant effect on service delivery of women entrepreneurs in South-western Nigeria is rejected.

Table 4 shows that unit increase in work demands will lead to 0.219 unit increase in service delivery among women entrepreneurs. A unit increase in family workload, well-being and spousal support will lead to 0.101, 0.061 , and 0.563 unit increase in service delivery among women entrepreneurs in the informal sector. All the explanatory variables have a positive impact on the explained variable. The probability variables values which are less than 0.05 means the variables are statistically significant.

These findings are in line with findings from Talreja (2017) that most of the women are overwhelmed by the conflicts that arise from domestic and entrepreneurial duties. Also Ugwu, Orjiakor, Enwereuzor, Onyedibeand Ugwu, (2016) discovered that well-being is viewed as the most important element of people's lives and it is associated with a wide variety of positive outcomes such as good health and work performance. This is also in line with the assertions of Dijkhuizen, Gorgeivsk, Veldhoven and Schalk (2014) that entrepreneurs can achieve an important competitive advantage over other entrepreneurs if they can learn to deal effectively with job demands and work-related strain. The traditional female roles are sometimes overwhelming especially when there is no support, and this can undermine women entrepreneur's self-confidence and the ability to assert themselves and succeed in business. Hence, a woman who runs a business must consider the effect on other facets of her life, including hobbies, personal relationships and family. These roles can impact work outputs and outcomes which invariably may have effect on her entrepreneurial performance.

\section{CONCLUSION AND RECOMMENDATION}

In conclusion, most women find the challenges of being an entrepreneur itself overwhelming as they have to combine this with their statutory roles. Balancing work and life roles has been proven to be a major contributor to performance of women entrepreneurs. Work demands have great influence on entrepreneurial performance as these women entrepreneurs are solely responsible for the success and overall outcome of their businesses. The number of hours they put in, the quality of time spent on the business and other work commitments have impact on their business growth and overall performance. Also, in the family domain, family workload which comprised the number and age of children, dependent care, parental demands, number of hours spent on family activities and family commitments contributed to the performance of women entrepreneurs. Women who perceive greater levels of responsibility from their families were more likely to struggle with their performance in the business front. Therefore, the study recommends that women 
entrepreneurs should effectively manage their work and family roles, ensure creativity and flexibility in their work domains and seek support to enable them to deliver eff- icient service and achieve overall performance in their business.

\section{REFERENCES}

Abdulraheem, I. (2014). The Changing Nature of Work-Life Balance in Nigerian Higher Institutions. Journal of Business and Management, 16(4), 61-66.

Ahmad, A. (2010). Work-Family Conflict among Junior Physicians: Its' Mediating Role in the Relationship between Role Overload and Emotional Exhaustion. Journal of Social Sciences 6 (2), 265-271.

Bakker, A.B., Demerouti, E. (2007). The Job Demands-resources Model: State of the Art. Journal of Managerial Psychology, $22,309-328$.

Dijkhuizen, J., Van Veldhoven, M., \& Schalk, R. (2014). Development and Validation of the Entrepreneurial job demands scale. International Journal of Knowledge, Innovation and Entrepreneurship, 2, 70-88.

Drnovsek, M., Örtqvist, D., Wincent, J. (2010). The Effectiveness of Coping Strategies Used by Entrepreneurs and Their Impact on Personal Well-being and Venture Performance. Journal of Economics and Business, 28, $193-220$.

Eby, L.T., Casper, W.J., Lockwood, A., Bordeaux, C., Brinley, A. (2005). Work and Family Research: Content Analysis and Review of the Literature (1980-2002). Journal of Vocational Behavior, 66, 124-197.

Edwards, J.R., Rothbard, N.P. (2000). Mechanisms Linking Work and Family: Clarifying the Relationship Between Work and Family Constructs. Academy of Management Review. 25 178-199.

Hair, J.F., Hult, G.T.M., Ringle, C., Sarstedt, M. (2014). A Primer on Partial Least Squares Structural Equations Modeling (PLSSEM). Thousand Oaks: Sage

Kirchmeyer, C. (2000). Work-life Initiatives: Greed or Benevolence Regarding Workers' Time? In C.L.Cooper, D.M. Rousseau (Eds.), Trends in Organizational Behavior, 7, 79-93.

Lavassani, K.M, Movahedi, B. (2018). Developments in Theories and Measures of Work-Family Relationships: From Conflict to Balance. Contemporary Research on Organization Management and Administration, 2(1), 1-19

Leiter, M.P., Bakker, A.B., Maslach, C. (2014). The Contemporary Context of Job Burnout. In M.P. Leiter, A.B. Bakker, C. Maslach (Eds.), Burnout at Work: A Psychological Perspective. Hove, Sussex: Psychology Press

Lodorfos, G., Kostopoulos, I., Kaminakis, K (2015). The Impact of Service Delivery System Effectiveness on Service Quality: A Hierarchical Approach. International Journal of Business Performance Management, 16(2/3)169.

Lovelock, C.H., Wright, L. (2002). Principles of Service Management and Marketing. New Jersey, USA: Prentice-Hall, Englewood Cliffs.

McGowana, P., Redeker, C.L., Cooper, S.Y., Greenan, K. (2012). Women Entrepreneurship and the Management of Business and Domestic Roles: Motivations, Expectations and Realities. Entrepreneurship \& Regional Development, 24(1-2), 5372.

Mullen, R., Lambie, G. (2016). The Contribution of School Counsellors Self-efficacy to Their Programmatic Service Delivery. Psychology in Schools, 53(3), 306-320.

Ojo, I.S., Salau, O.P., Falola, H.O. (2014). Work Life Balance Practices in Nigeria a Comparison of Three Sector Journal on Competitiveness. Journal of Competitiveness, 6(2), 3-14.

Schaufeli, W.B., Bakker, A.B. (2004). Utrecht Work Engagement Scale, Preliminary Manual. Occupational Health Psychology Unit, Utrecht University.

Talreja, M. (2017). Women Entrepreneurship and Work Life Balance. Global Journal of Human - Social Science (H), 17(6), 10. 
Ugwu, D.I., Orjiakor, C.T., Enwereuzor, I.K., Onyedibe, C.C., Ugwu, L.I. (2016). Business-life Balance and Wellbeing: Exploring the Lived Experiences of Women in a Low To-middle Income Country. International Journal of Qualitative Studies on Health and Well-being, 11.

Vargo, S.L., Robert, F.L. (2008). "Why Service?”, Journal of the Academy of Marketing Science, 36 (1), 25-38. 